\title{
FATORES ASSOCIADOS À VIOLÊNCIA SEXUAL CONTRA MULHERES: ANÁLISE DE OCORRÊNCIAS POLICIAIS
}

\author{
Cristiane Lopes Amarijo ${ }^{1}$, Daniele Ferreira Acosta², Camila Daiane Silva², Vera Lúcia de Oliveira Gomes ${ }^{3}$
}

${ }^{1}$ Enfermeira. Mestranda em Enfermagem. Universidade Federal do Rio Grande. Rio Grande-RS-Brasil. ${ }^{2}$ Enfermeira. Doutoranda em Enfermagem. Universidade Federal do Rio Grande. Rio Grande-RS-Brasil. ${ }^{3}$ Enfermeira. Doutora em Enfermagem. Universidade Federal do Rio Grande. Rio Grande-RS-Brasil.

Resumo: Estudo documental, quantitativo e exploratório-descritivo. Objetivou conhecer o perfil das vítimas, agressores e caracterizar a violência sexual registrada em uma Delegacia para Mulheres, entre agosto/2009 e dezembro/2011. Os dados coletados foram inseridos em planilhas do Aplicativo Microsoft Excel $($ e tratados por meio da estatística descritiva e de números absolutos e relativos. Nas 39 analisadas, houve prevalência de vítimas com idade entre 20 e 30 anos, cor branca, ensino fundamental e com trabalho remunerado. Prevaleceu a violência praticada por homens desconhecidos, com 30 a 40 anos, brancos, ensino fundamental e trabalhadores na construção civil. A força física foi a intimidação mais utilizada para cometer o estupro, sendo a via pública o principal cenário. A maioria das vítimas realizou exame pericial. Muitos aspectos culturais, crenças e valores interferem ou inibem a denúncia de tais crimes. Cabe a enfermagem atuar tanto na recuperação e promoção da saúde das vítimas, quanto em ações de prevenção. Palavras-chave: Violência sexual; Violência contra a mulher; Saúde sexual e reprodutiva; Enfermagem.

\section{FACTORS ASSOCIATED WITH SEXUAL VIOLENCE AGAINST WOMEN: ANALYSIS OF POLICE REPORTS}

\begin{abstract}
A documentary, quantitative and exploratorydescriptive study. It aimed to understand the profile of the victims and the aggressors and to characterize sexual violence registered in a Women's Police Station from August/2009 to December/2011. The collected data were entered into Microsoft Excel ${ }^{\circledR}$ spreadsheets and analysed by means of descriptive statistics and absolute and relative numbers. Among the 39 cases analyzed, there was a prevalence of victims with ages ranging from 20 to 30 years old, white, elementary education and with paid employment. Violence committed by unknown men prevailed, 30-40 years old, white, elementary education and construction workers. Physical force was the most used intimidation form to commit rape, and the public roads were the main scenario. Most of the victims were submitted to forensic examination. Many cultural aspects, beliefs and values interfere or inhibit the reporting of such crimes. It is nursing's responsibility to act both in health promotion and recovery of the victims, including preventive actions. KEYWORDS: Sexual Violence; Violence against women; Sexual and reproductive health; Nursing.
\end{abstract}

\section{FACTORES ASOCIADOS A LA VIOLENCIA SEXUAL CONTRA MUJERES: ANÁLISIS DE OCURRENCIAS POLICIALES}

RESUMEN: Estudio documental, cuantitativo y exploratoriodescriptivo. Su finalidad fue conocer el perfil de las víctimas, los agresores y caracterizar la violencia sexual registrada en una Comisaría para Mujeres, entre agosto/2009 y diciembre/2011. Los datos recogidos fueron dispuestos en planillas del Aplicativo Microsoft Excel® y trabajados por medio de la estadística descriptiva y de números absolutos y relativos. De las 39 analizadas, hubo prevalencia de víctimas con edad entre 20 y 30 años, color blanco, enseñanza fundamental y con trabajo remunerado. Ha prevalecido la violencia practicada por hombres desconocidos, con 30 a 40 años, blancos, enseñanza fundamental y trabajadores en la construcción civil. La fuerza física fue la intimidación más utilizada para el estupro, siendo la vía pública el principal escenario. La mayoría de las víctimas realizó examen pericial. Muchos aspectos culturales, creencias y valores interfieren o inhiben la denuncia de tales crímenes. Es responsabilidad de la enfermería actuar tanto en la recuperación y promoción de la salud de las víctimas, cuanto en acciones de prevención. DESCRIPTORES: Violencia sexual; Violencia contra la mujer; Salud sexual y reproductiva; Enfermería. 


\section{INTRODUÇÃO}

A violência sexual é uma brutal violação dos direitos humanos, sexuais e reprodutivos ${ }^{(1-2)}$ e, quando direcionada à mulher, representa uma manifestação do domínio masculino. Dessa forma, "a violência sexual não somente é reveladora da desigualdade de gênero, mas também é emblemática desta"13:122).

Essa forma de violência é exercida quando a vítima, mediante ameaças ou uso da força, é obrigada a participar, manter ou presenciar relação sexual indesejada. Tais situações podem se concretizar sob a forma de carícias, exposição a material pornográfico, negação do parceiro em utilizar preservativos, sexo forçado durante o namoro, noivado ou casamento, além de atitudes e gestos obscenos no trato com as mulheres ${ }^{(1,3)}$.

Mundialmente estima-se que a cada ano, cerca de doze milhões de pessoas sejam vitimadas sexualmente ${ }^{(3)}$. Aproximadamente, seis em cada dez mulheres são submetidas a algum tipo de violência física ou sexual, ao longo de suas vidas ${ }^{(4)}$. Entre $6 \%$ e $59 \%$ já foram abusadas sexualmente por parceiros íntimos, após completarem 15 anos de idade ${ }^{(1)}$. O abuso por não parceiro também é frequente configurando uma realidade endêmica ${ }^{(5)}$.

Mulheres que sofrem violência doméstica pelo parceiro íntimo, apresentam maiores chances de sofrerem violência sexual|(3). Uma pesquisa realizada em El Salvador, em 2008, com 7.349 mulheres, revelou que $12 \%$ delas, em algum momento de suas vidas, foram submetidas a situação de sexo forçado pelo parceiro íntimo(1).

Apesar desses dados reveladores, estimase que $10 \%$ dos casos de violência sexual são denunciados ${ }^{(6-7)}$. As justificativas para a subnotificação centram-se nas chantagens e ameaças dos agressores às vítimas. Além disso, a vergonha, a humilhação e a sensação de culpa pelo ocorrido, associado à descrença na punição e o temor de um confronto com o agressor, também constituem barreiras à denúncia ${ }^{(3)}$.

A fragilidade do sistema, morosidade institucional e dos trâmites legais também são apontadas, por algumas vítimas, como inibidores das denúncias. Essas mulheres referem que a lentidão dos processos as deixam inseguras e em situação de vulnerabilidade ${ }^{(8)}$.
Sabe-se que a violência sexual tem efeitos imediatos e tardios nas esferas física e mental da vítima. Destacam-se os elevados índices de abortamento e gravidez indesejada, exposição a doenças sexualmente transmissíveis, depressão, ansiedade, isolamento social, entre outros ${ }^{(2)}$. Diante da magnitude do fenômeno, considerase a violência sexual contra mulheres um grave problema de saúde pública, sendo ímpar o estabelecimento de ações, e intervenções sociais para o seu enfrentamento, prevenção, tratamento e recuperação das vítimas.

Para tanto, é necessário trabalho multidisciplinar incluindo diversos campos do conhecimento como o jurídico, político, religioso, educacional e de saúde. Aos enfermeiros, co-responsáveis pelo cuidado, cabe o papel de educador em saúde, de promotor do empoderamento das vítimas de violência sexual, bem como a problematização da equidade de gênero nos diversos espaços de atuação. Para isso, é importante compreender o contexto da violência sexual contra a mulher, o que requer o conhecimento de aspectos pontuais. Por conseguinte, realizou-se este estudo com os objetivos de conhecer o perfil das vítimas e dos agressores, bem como caracterizar a violência sexual registrada em uma Delegacia Especializada no Atendimento às Mulheres (DEAM).

\section{METODOLOGIA}

Pesquisa documental, exploratória descritiva, de abordagem quantitativa e delineamento transversal, realizada na DEAM do município do Rio Grande-RS-Brasil. Constitui um recorte do projeto intitulado "Violência de gênero registrada na Delegacia de Polícia Especializada no Atendimento às Mulheres no município do Rio Grande-RS". Desde sua implantação, em agosto de 2009, até dezembro de 2011 foram registrados nessa DEAM, aproximadamente, 3.000 ocorrências referentes à violência contra a mulher, crianças e adolescentes. Fizeram parte deste estudo todas as ocorrências policiais, referentes a violência sexual contra mulheres, com idade igual ou superior a 18 anos. Os dados foram colhidos, entre outubro de 2011 e março de 2012, diretamente das ocorrência policiais contidas nos arquivos da delegacia nesse período, por meio de planilhas do Aplicativo Microsoft Exce/ $\mathbb{R}$, 
construídas especificamente para essa pesquisa. Foram excluídas as ocorrências que tramitavam em outras instâncias do judiciário e as referentes as mulheres com idade inferior a 18 anos.

As variáveis independentes pesquisadas para delinear o perfil da vítima e do agressor foram: idade, cor da pele, grau de instrução, ocupação, grau de parentesco, uso de drogas ilícitas por parte do agressor e antecedentes criminais. Da violência sexual colheram-se as seguintes informações: local de abordagem da vítima, tipo de crime praticado, forma de intimidação, realização do exame pericial, ou seja do exame de corpo de delito.

Para o tratamento dos dados utilizou-se a estatística descritiva por meio de números absolutos e relativos, com os quais foram construídas tabelas para ilustrar a apresentação dos resultados. $\mathrm{O}$ estudo atendeu às normas de ética em pesquisa envolvendo seres humanos, sendo aprovado pelo Comitê de Ética em Pesquisa sob parecer No 137/2011.

\section{RESULTADOS}

Para a apresentação dos resultados inicialmente descreveu-se o perfil das 39 mulheres que sofreram violência sexual e dos 39 agressores e, a seguir apresentaram-se as características da violência a que foram submetidas as vítimas.

\section{Perfil das vítimas}

Os dados revelaram que a idade das vítimas variou entre 18 e 68 anos, com predomínio daquelas entre 20 e 29 anos (41\%) seguida da faixa entre 30 e 40 anos (25,6\%). Destacam-se dois casos de violência sexual contra mulheres maiores de 60 anos, caracterizando a violência contra a pessoa idosa. Observou-se que 35 (89,7\%) vítimas eram de cor branca e 20 (51,3\%) possuíam o ensino fundamental completo ou incompleto. A maioria possuía alguma fonte de renda. Quanto ao parentesco da vítima com o agressor, em 53,9\% dos casos a violência foi cometida por pessoa desconhecida (Tabela 1).

\section{Perfil dos agressores}

$\mathrm{Na}$ análise efetuada acerca do perfil dos agressores 15 (38,5\%) tinham idade entre 30 e 39 anos, 28 (71,8\%) eram de cor branca e 23
Tabela 1 - Distribuição das mulheres que sofreram violência sexual segundo faixa etária, cor de pele, escolaridade, fonte de renda e grau de parentesco com o agressor. Rio Grande-RS-Brasil, 2014

\begin{tabular}{lcc}
\hline Faixa etária & $\mathbf{n}$ & $\mathbf{\%}$ \\
\hline 18 a 20 anos & 04 & 10,3 \\
\hline 20 a 30 anos & 16 & 41 \\
\hline 30 a 40 anos & 10 & 25,6 \\
\hline 40 a 50 anos & 03 & 7,7 \\
\hline 50 a 60 anos & 04 & 10,3 \\
\hline mais que 60 anos & 02 & 5,1 \\
\hline Cor da pele & $\mathbf{n}$ & $\%$ \\
\hline Branca & 35 & 89,7 \\
\hline Não branca & 04 & 10,3 \\
\hline Escolaridade & $\mathbf{n}$ & $\%$ \\
\hline Não-alfabetizada & 02 & 5,1 \\
\hline Ensino fundamental & 20 & 51,3 \\
\hline Ensino médio & 15 & 38,5 \\
\hline Ensino superior & 02 & 5,1 \\
\hline Fonte de renda & $\mathbf{n}$ & $\%$ \\
\hline Sim & 20 & 51,3 \\
\hline Não & 02 & 5,1 \\
\hline Não informado & 17 & 43,6 \\
\hline Parentesco com o \\
agressor
\end{tabular}

FONTE: Delegacia de Polícia Especializada no Atendimento às Mulheres, Rio Grande/RS, 2009-2011.

(59\%) possuíam o ensino fundamental completo ou incompleto. No que se refere à ocupação, 10 (25,6\%) estavam vinculados à construção civil, exercendo as funções de pedreiro e servente de pedreiro. Observou-se o uso de drogas ilícitas e antecedentes criminais em $13(33,3 \%)$ e 18 $(46,1 \%)$ casos, respectivamente (Tabela 2$)$.

\section{Características da violência sexual}

Quanto as características do ato violento, a via pública foi o sítio em que houve maiores índices da prática de violência sexual $(43,6 \%)$. Os agressores fizeram uso da força física em 27 $(69,2 \%)$ casos e de arma de fogo em 8 (17,9\%) como forma de intimidar as vítimas (Tabela 3). 
Destaca-se que, entre os agressores que utilizaram a força física para efetuar o crime sexual, a maioria era do convívio da vítima e a arma de fogo foi usada em grande parte por desconhecidos, como forma de intimidar as vítimas.

Ao analisar a tipificação da violência sexual, 30 (76,9\%) casos referiam-se ao estupro consumado. O exame pericial, também conhecido por Exame de Corpo de Delito, foi realizado por 22 (56,4\%) vítimas sendo que em 15 (38,5\%) ocorrências policiais não constavam esse dado.

Tabela2-Distribuição dosacusados segundoafaixa etária, cor depele, escolaridade, ocupação, uso de drogas ilícitas e antecedentes criminais. Rio Grande-RS-Brasil, 2014

\begin{tabular}{|c|c|c|}
\hline Faixa etária & $\mathbf{n}$ & $\%$ \\
\hline menos que 20 anos & 01 & 2,6 \\
\hline 20 a 30 anos & 09 & 23,1 \\
\hline 30 a 40 anos & 15 & 38,5 \\
\hline 40 a 50 anos & 06 & 15,3 \\
\hline 50 a 60 anos & 03 & 7,7 \\
\hline mais que 60 anos & 02 & 5,1 \\
\hline Não informado & 03 & 7,7 \\
\hline Cor da pele & $\mathbf{n}$ & $\%$ \\
\hline Branco & 28 & 71,8 \\
\hline Não branco & 08 & 20,5 \\
\hline Não informado & 03 & 7,7 \\
\hline Escolaridade & $\mathbf{n}$ & $\%$ \\
\hline Analfabetizado & 02 & 5,1 \\
\hline Ensino fundamental & 23 & 59 \\
\hline Ensino médio & 02 & 5,1 \\
\hline Ensino superior & 01 & 2,6 \\
\hline Não informado & 11 & 28,2 \\
\hline Ocupação/profissão & $\mathbf{n}$ & $\%$ \\
\hline Construção civil & 10 & 25,6 \\
\hline Motorista & 03 & 7,7 \\
\hline Dentista & 01 & 2,6 \\
\hline Desempregado & 04 & 10,2 \\
\hline Outros & 06 & 15,4 \\
\hline Não informado & 15 & 38,5 \\
\hline Uso de drogas ilícitas & $\mathbf{n}$ & $\%$ \\
\hline Sim & 13 & 33,3 \\
\hline Não & 01 & 2,6 \\
\hline Não informado & 25 & 64,1 \\
\hline Antecedentes criminais & $\mathbf{n}$ & $\%$ \\
\hline Sim & 18 & 46,1 \\
\hline Não & 13 & 33,3 \\
\hline Não informado & 08 & 20,5 \\
\hline
\end{tabular}

FONTE: Delegacia de Polícia Especializada no Atendimento às Mulheres, Rio Grande/RS, 2009-2011.
Tabela 3 - Distribuição dos casos de violência sexual segundo o local, forma de intimidação, tipificação do crime e realização do exame pericial pelas vítimas. Rio Grande-RS-Brasil, 2014

\begin{tabular}{|c|c|c|}
\hline Local do crime & $\mathbf{n}$ & $\%$ \\
\hline Via pública & 17 & 43,6 \\
\hline Residência da vítima & 09 & 23,1 \\
\hline Residência de ambos & 07 & 17,9 \\
\hline Residência do acusado & 04 & 10,3 \\
\hline Outro & 02 & 5,1 \\
\hline $\begin{array}{l}\text { Forma de intimidação/ } \\
\text { Agressor }\end{array}$ & $\mathbf{n}$ & $\%$ \\
\hline Uso de força física & 27 & 69,2 \\
\hline Chefe & 01 & 3,7 \\
\hline Companheiro & 03 & 11,1 \\
\hline Ex-companheiros & 06 & 22,3 \\
\hline Conhecidos & 01 & 3,7 \\
\hline Padrasto & 02 & 7,4 \\
\hline Filho & 01 & 3,7 \\
\hline Vizinhos & 01 & 3,7 \\
\hline Outros familiares & 01 & 3,7 \\
\hline Desconhecidos & 11 & 40,7 \\
\hline Arma de fogo & 08 & 17,9 \\
\hline Conhecido & 01 & 12,5 \\
\hline Desconhecido & 07 & 87,5 \\
\hline Ameaça & 03 & 7,7 \\
\hline Companheiro & 01 & 33,3 \\
\hline Cunhado & 01 & 33,3 \\
\hline Desconhecido & 01 & 33,3 \\
\hline Outras formas & 01 & 5,2 \\
\hline Tipificação do crime & $\mathbf{n}$ & $\%$ \\
\hline Estupro & 30 & 76,9 \\
\hline Tentativa de estupro & 07 & 17,9 \\
\hline Assédio sexual & 01 & 2,6 \\
\hline Outros crimes consumados & 01 & 2,6 \\
\hline Exame pericial & $\mathbf{n}$ & $\%$ \\
\hline Sim & 22 & 56,4 \\
\hline Não & 02 & 5,1 \\
\hline Não informado & 15 & 38,5 \\
\hline
\end{tabular}

FONTE: Delegacia de Polícia Especializada no Atendimento às Mulheres, Rio Grande/RS, 2009-2011. 


\section{DISCUSSÕES}

A violência sexual tem sido pauta de diversos estudos nacionais ${ }^{(6)}$ e internacionais ${ }^{(1-2,5)}$ com o objetivo de dar visibilidade à temática, por meio de dados estatísticos que suscitem a compreensão da prevalência desse fenômeno na população de diferentes países e regiões.

Neste estudo, o perfil das vítimas demonstrou a prevalência da violência sexual entre mulheres jovens, brancas e com baixo nível de escolaridade. Corroborando com os achados de estudo realizado em Delegacias Especializadas de Atendimento à Mulher da região metropolitana do Rio de Janeiro, o qual evidenciou que entre as vítimas predominava as de cor branca, o que não significa que elas sejam as mais vitimadas, e sim que essas mulheres "são reconhecidas por denunciarem mais a agressão"(7:439).

O baixo grau de instrução encontrado, associado a outros determinantes, permite refletir que há certa correlação entre fatores socioeconômicos e individuais e o risco de sofrer violência sexual(1). Quando se trata da agressão praticada pelo parceiro íntimo, investigação realizada na Bolívia, Colômbia, República Dominicana, Haiti e Peru revelou que a maior parte das mulheres apresentava baixa escolaridade. $\mathrm{Na}$ referida pesquisa os autores apregoam que o risco de sofrer violência sexual por parceiro íntimo diminui conforme aumenta o nível de escolaridade das mulheres ${ }^{(1)}$.

Ao analisar a situação financeira das vítimas, percebeu-se que 20 (51,3\%) possuíam fonte de renda proveniente do trabalho doméstico, ou seja, com baixa remuneração. Mulheres financeiramente dependentes de seus parceiros tendem a subnotificar a violência sofrida por não acreditarem na própria capacidade de prover a família, por medo do agressor ou por acreditarem que ficar com o companheiro é o melhor para seus filhos ${ }^{(7)}$.

Neste estudo, em 53,9\% dos casos o agressor era desconhecido da vítima e em $25,6 \%$ o parceiro íntimo. Este fato se assemelha aos resultados de estudo realizado com vítimas de violência sexual, atendidas em um hospital universitário, onde os principais agressores eram estranhos ${ }^{(9)}$. Esse dado chama atenção e revela que quando se trata da violência sexual cometida por estranhos, fatores macrossômicos como questões culturais, normas sociais, políticas de saúde e educacionais surgem como catalisadores do fenômeno, podendo contribuir para incitar atos violentos.

Embora na maioria dos casos não houvesse parentesco entre a vítima e o agressor, homens do convívio íntimo, entre eles os próprios parceiros, filho, padastro e cunhado também praticaram o ato violento. Nos casos de violência praticada pelo cônjuge é comum a associação de diferentes tipos de violência ${ }^{(10)}$. O desejo de separação conjugal por parte da mulher e o ciúmes do parceiro associados ao uso de álcool e drogas são motivos citados como desencadeantes das agressões ${ }^{(11-12)}$.

Quanto ao perfil do acusado, a faixa etária encontrada nesse estudo assemelha-se a uma pesquisa realizada no Serviço de Atenção a Pessoas em Situação de Violência Sexual, de Salvador-BA, em que a idade dos agressores foi entre 20 e 40 anos $^{(13)}$. Em relação à ocupação, a maioria trabalhava na construção civil como pedreiros e serventes de pedreiro. A baixa escolaridade associada a baixa remuneração, evidenciada neste estudo, constituiu um flagelo na ocorrência do fenômeno.

Os homens que cometem crimes sexuais constituem um grupo muito heterogêneo, variando desde pessoas condenadas por um único episódio de crime sexual, até estupradores em série e homicidas sexuais ${ }^{(14)}$. Na presente pesquisa, 46,1\% dos agressores possuiam antecendentes criminais.

Ao caracterizar o ato violento verificou-se que os crimes ocorreram majoritariamente na via pública (43,6\%) seguido da residência da vítima $(23,1 \%)$. No entanto, considerando-se a totalidade dos crimes, enfatiza-se que houve predomínio de locais de convívio dos envolvidos como, por exemplo, a residência da vítima, do agressor ou de ambos. Evidencia-se que os agressores, quando conhecidos das vítimas, dão preferência aos locais livres da interferência de terceiros, ou seja, locais que Ihes são bem conhecidos e que possam garantir o domínio sobre a mulher ${ }^{(10,13)}$. Por outro lado, segundo os dados empíricos desta e de outras pesquisas, quando praticado por desconhecidos, a esfera pública é o local onde mais frequentemente ocorre a prática do crime ${ }^{(9)}$.

Neste estudo detectou-se que em $69,2 \%$ dos casos os agressores fizeram uso da força física para efetivar a violência, forma muito comum de intimidação(9). Esses dados assemelham-se aos encontrados entre mulheres que sofreram violência sexual e foram atendidas no Centro de Atenção Integral à Saúde da Mulher em Campinas ${ }^{(15)}$. 
O emprego dessa forma de intimidação revela o desejo que o homem tem de mostrar poder, humilhar, aterrorizar, dominar ${ }^{(16)}$ e manter o controle da vítima. Consecutivamente, encontra-se o uso da arma de fogo, evidenciado em 17,9\% das ocorrências policiais. Ao realizar associação entre a forma de intimidação e o parentesco com a vítima revela-se que a força física foi cometida por pessoas do convívio social da mulher (59,3\%) enquanto a arma de fogo por agressores desconhecidos (87,5\%).

A forma de violência sexual mais prevalente foi o estupro e a tentativa de estupro com $76,9 \%$ dos casos e 17,9\%, respectivamente. Esses crimes representam atualmente um problema de saúde pública tanto pela elevada incidência quanto pelas graves consequências emocionais e físicas à saúde da mulher ${ }^{(6,17)}$. Embora seja um fenômeno de grande magnitude e impacto, ainda permanece oculto na sociedade, pois reduzido é o número de vítimas que realizam a denúncia ${ }^{(6)}$.

Quanto ao exame pericial, principal meio para a comprovação do fato, identificação e criminalização do acusado, percebeu-se que mais da metade das vítimas $(56,4 \%)$ o realizaram. Contudo, em muitas das ocorrências analisadas, esse dado não constava. De acordo com o Ministério da Saúde, essa prova também pode ser obtida de forma indireta, através da análise do prontuário da paciente, na instituição de saúde onde foi atendida. Nesse sentido, destaca-se o papel do profissional de saúde, diante da assistência às vítimas de violência sexual, responsável pelo registro detalhado do exame físico, das características das lesões genitais e anais ${ }^{(3)}$.

Nos casos de violência sexual com penetração também é recomendado que o início do tratamento com antirretrovirais e a anticoncepção de emergência ocorra até 72 horas após a violência, pois passado esse período a eficácia medicamentosa reduz significativamente, fornecendo menor proteção $^{(3)}$. Novamente cabe aos profissionais da saúde a orientação acerca desses aspectos, bem como a problematização e prevenção de novos agravos à saúde dessas mulheres.

\section{CONCLUSÕES}

O estudo retrata o perfil das vítimas, seus agressores e as características da violência sexual, denunciadas em uma delegacia especializada ao atendimento às mulheres. Trata-se, contudo de uma visão parcial, tanto por se restringir a um período, quanto por se referir a um local específico. No entanto, sua fundamental relevância está atrelada ao dimensionamento do problema, o qual pode servir de alerta a profissionais de diversos campos do conhecimento acerca da magnitude do fenômeno.

Uma das limitações detectadas nesta pesquisa documental foi a falta de uniformidade nos registros, uma vez que alguns dados referentes às variáveis estudadas estavam incompletos. A violência sexual acometeu, principalmente, mulheres com baixo nível de escolaridade porém, essa situação não exclui a ocorrência do fenômeno entre pessoas com níveis mais elevados de instrução ou melhores condições financeiras.

Homens desconhecidos das vítimas foram os principais responsáveis pela prática dos estupros e tentavivas de estupo, sendo a força física o meio de intimidação mais utilizado seguido da arma de fogo. Duas mulheres não realizaram o exame pericial como forma de obter a prova criminal e a indentificação do agressor. Esse dado não constava em 15 boletins de ocorrência, o que poderia elevar o número das que realizaram ou representar a possível falta de informação das vítimas quanto a importância da realização do referido exame.

Os resultados apresentados limitam-se ao contexto social onde o estudo foi realizado refletindo os crimes cometidos a uma determinada população. Entretanto, a violência sexual acomete mulheres em todo o mundo, independente de suas condições socioeconômicas e culturais.

Em virtude dessa situação, os profissionais da saúde, em especial os enfermeiros, devem estar capacitados para atuar junto às mulheres com vistas a informar-lhes sobre os locais onde devem buscar atendimento e realizar a denúncia. Ainda, devem empoderar as mulheres acerca dos seus direitos enquanto cidadãs, para que, assim, se possa transformar o cenário de violência sexual. A problematização dos aspectos que envolvam a denúncia do agressor, como forma de romper o ciclo da violência, bem como dos direitos femininos, instituídos pela Lei Maria da Penha, demonstra que para o enfrentamento do fenômeno é necessário a atuação interdisciplinar, com profissionais coesos e sensíveis ao problema. Aos profissionais da saúde ainda, cabe conhecer 
seus deveres em relação à notificação compulsória dos casos de violência suspeitos ou confirmados, como forma de contribuir na visibilidade do fenômeno.

Destaca-se, ainda, que os enfermeiros devem atuar no processo de recuperação das vítimas e, em igual importância, realizar ações educativas junto à população masculina com o intuito de desnaturalizar a prática da violência de gênero.

Por fim, para combater a violência sexual é necessária a implementação de Políticas Públicas: nacional, estadual e municipal, bem como equipes multiprofissionais capacitadas e articuladas para por em prática a legislação e para o adequado atendimento às vítimas, por meio da tomada de decisões éticas e competentes.

\section{REFERÊNCIAS}

1. Contreras JM, Bott S, Guedes A, Dartnall E. Violencia sexual en Latinoamérica y El Caribe: Análisis de datos secundarios. Iniciativa de Investigación sobre la Violencia Sexual. [Internet] 2010; [acesso em 18 mar 2013]. Disponível: http://www.oas.org/dsp/ documentos/Observatorio/violencia_sexual_la_y_ caribe_2.pdf

2. World Health Organization. Global and regional estimates of violence against women: prevalence and health effects of intimate partner violence and non-partner sexual violence. Geneva. [Internet] 2013; [acesso em 05 ago 2014]. Disponível: http://apps.who. int/iris/bitstream/10665/85239/1/9789241564625_eng. pdf?ua $=1$

3. Ministério da Saúde (BR). Secretaria de Atenção à Saúde. Departamento de Ações Programáticas Estratégicas. Prevenção e tratamento dos agravos resultantes da violência sexual contra mulheres e meninas: norma técnica. Ministério da Saúde. Secretaria de Atenção à Saúde. $3^{\mathrm{a}}$ ed. Brasília: Editora do Ministério da Saúde, 2012.

4. UN Women. [homepage na internet] 2009; [acesso em 03 out 2013]. Disponível em: http://www.unwomen. org/em.

5. Abrahams N, Devries K, Watts C, Pallitto C, Petzold $M$, Shamu $S$, et al. Worldwide prevalence of nonpartner sexual violence: a systematic review. The Lancet. [Internet] 2014;383 (9929). [acesso em 05 ago 2014]. Disponível: http://download.thelancet. com/pdfs/journals/lancet/PIIS0140673613622436. pdf?id=baaCNT64shoCodx6aWGFu

6. Cerqueira D, Coelho DSC. Estupro no Brasil: uma radiografia segundo os dados da saúde [Internet]
2014; [acesso em 13 ago 2014]. Disponível: http:// www.ipea.gov.br/portal/images/stories/PDFs/nota_ tecnica/140327_notatecnicadiest11.pdf

7. Moura MAV, Albuquerque Netto L, Souza MHN. Perfil sociodemográfico de mulheres em situação de violência assistidas nas delegacias especializadas. Esc. Anna Nery. 2012;16 (3):435 - 442.

8. Tavares MS, Sardenberg CMB, Gomes MQC. Feminismo, estado e politica de enfrentamento à violencia contra mulheres: monitorando a Lei Maria da Penha. Estud. fem. [Internet] 2012; [acesso em 15 abr 2013]. Disponível: http://www.tanianavarroswain. com.br/labrys/labrys20/brasil/lei\%20MP.htm

9. Facuri CO, Fernandes MAS, Oliveira KD, Andrade TS. Violência sexual: estudo descritivo sobre as vítimas e o atendimento em um serviço universitário de referência no Estado de São Paulo, Brasil. Cad. saude publica. 2013; 29(5):889-898.

10. Borrego MAR, Vaquero-Abellán M, Rosa LB. A crosssectional study of factors underlying the risk of female nurses' suffering abuse by their partners. Rev. LatinoAm. Enfermagem. 2012;20(1):11-8.

11. Leôncio $K L$, Baldo $P L$, João VM, Biffi RG. Pofile of victimized women and of their aggressors. Rev. enferm. UERJ. 2008;16(3):307-12.

12. Carvalho C, Destro JR, Faust SB, Coelho EBS. Dinâmica da violência entre casais a partir da ótica da mulher agredida no bairro Trindade, Florianópolis/SC. Cogitare enferm. 2010;15(4):603-8.

13. Diniz NMF, Almeida LCG, Ribeiro BCS, Macêdo VG. Women victims of sexual violence: adherence to chemoprevention of HIV. Rev Latino-Am. Enfermagem. 2007;15(1):7-12.

14. Ribeiro RB, Lee JB, Cordeiro Q. Sex offenders: risk assessment, risk factors and management. Revista de Criminologia e Ciências Penitenciárias. 2012;2(3).

15. Oshikata CT, Bedone AJ, Papa MSF, Santos GB, Pinheiro $\mathrm{CD}$, Kalies $\mathrm{AH}$. Characteristics of women victims of sexual violence and their compliance with outpatient follow-up: time trends at a referral center in Campinas, São Paulo State, Brazil. Cad. Saude Publica. 2011;27(4):701-713.

16. Trindade RFC, Almeida AM, Rozendo CA. Infidelidade masculina e violência doméstica: vivência de um grupo de mulheres. Cienc. enferm. 2008; (2): 39-46.

17. Raimondo ML, Labronici LM, Larocca LM. Retrospecto de ocorrências de violência contra a mulher um registradas em uma delegacia especial. Cogitare enferm. 2013;18(1):43-9. 